\title{
ELEMENTE AVANGARDISTE ÎN PERIOADA POSTBELICĂ
}

\author{
Dordea Daniela Elisabeta
}

Universitatea „Lucian Blaga” din Sibiu

\begin{abstract}
In this article we discuss the avant-garde phenomenon, emphasizing that it promotes thinking without prejudice or limits, in which the writer can explore completely new horizons of creativity. Both Virgil Mazilescu's poems and Nora Iuga's poems (both under the oneiric mantle), illustrate the idea of freedom in terms of poetic thinking and poetry, despite the political and literary context in which they were.
\end{abstract}

Key Words: poems, oneiric, Mazilescu, Iuga

Etimologic vorbind, termenul avangardă $\breve{a}^{1}$ provine din limba franceză. În 1870 termenul ,a ajuns să desemneze micul grup de scriitori și artiști novatori care au transferat spiritul criticii radicale a formelor sociale în domeniul formelor artistice”, afirmă Matei Călinescu în Cele cinci fețe ale modernităţii. Tot el explică faptul că pentru artiștii avangardei important era să

\footnotetext{
${ }^{1}$ Avangardă: Unitate sau subunitate militara care se deplaseaza înaintea fortelor principale pentru a le asigura securitatea. $\bullet$ De $\sim$ principal; de frunte. Mișcare artistică inovatoare. Mișcare artistică având rol de precursor pentru alte mișcări moderniste. / frr. avant-garde (Dicționar explicativ al limbii române).
} 
, răstoarne toate tradițiile formale constrângătoare ale artei și să se bucure de libertatea amețitoare de a explora orizonturi de creativitate cu totul noi.”.

Ion Pop în Avangarda în Literatura Română $\breve{a}^{2}$ vorbește despre două atitudini privind fenomenul avangardist, și anume: „ruptura, negarea radicală a tradiției cultural literare și aspirația către o absolută înnoire a limbajului."3 $\mathrm{Cu}$ alte cuvinte acest fenomen neagă vechiul, afirmă noul și totodată libertatea absolută a spiritului. Astfel apar tehnci menite să acorde libertate imaginației și care sunt opuse logicii constrângătoare, cum ar fi suprarealistul „dicteu automat”. Termenul provine din limba franceză $(<$ fr. dictée automatique, scriere auto-mată $<$ gr. autómatos=,,mişcare automată) și este ”o formă practică de scriitură aplicată în mod voluntar şi afirmată programatic de către suprarealişti prin care se urmărea notarea fluxului spontan al gândirii, nemediate raţional." ${ }^{4}$ Tot Ion Pop, în lucrarea amintită, afirmă că toate orientările avangardiste se autodefinesc drept stări de spirit, aceste stări fiind definite de ceea ce el numea obsesii a dinamismului absolut al spiritului creator, lecția majoră a avangardei, spune el, "constă în cultivarea acelei stări de disponibilitate absolută a spiritului creator."

$\mathrm{Nu}$ se poate vorbi despre fenomenul avangardist fără a aduce în discuție revistele de avangardă. Menționăm în primul rând revista Contimporanul (condusă de Ion Vinea). Primul exemplar apare în iulie 1923. De asemenea prezente sunt și revistele Unu, Urmuz, Alge, Integral Ş.a. care au promovat tendințele curentului avangardist. Un element definitoriu pentru a evidenția importanța acestor reviste este apariția manifestelor. Poetul avangardist își exprimă nemulțumirea într-un mod direct, îndrăzneț, agresiv chiar, bazându-se pe puterea de sugestie a limbajului. Cel mai concret, tranșant și răsunător exemplu de manifest este cel apărut în 16 mai 1924 (nr.46) în Contimporanul: Manifest activist către tinerime scris de Ion Vinea ("stârpim prin forţa desgustului propagat, stafiile cari tremură de lumină. / Să ne ucidem morţii" ${ }^{5}$.).

Avangarda aduce cu ea o serie de miscări. De pildă: expresionismul, dadaismul, constructivismul, integralismul, suprarealismul etc. Oprindu-ne la mișcarea suprarealistă, aceasta este definită de André Breton în primul Manifest al Suprarealismului (1924) ca fiind un

\footnotetext{
${ }^{2}$ POP Ion, Avangarda în literatura română, București, Editura: Atlas, 1999.

${ }^{3}$ Ibid. pp. 5-23.

${ }^{4}$ http://www.revista-astra.ro/literatura/files/2013/01/rodica-ilie1.pdf, Dicționarul avangardelor, Rodica Ilie.

5 http://dspace.bcucluj.ro/bitstream/123456789/13603/1/BCUCLUJ_FP_P2960_1924_003_0046.pdf, 16 mai 1924

(nr.46) Manifest activist către tinerime. p. 10.
} 
"automatism psihic în forma sa cea mai pură, prin care individul poate exprima - atât sub formă verbală, cât și în orice altă formă - funcționarea exactă a gândului." "6 Breton vorbește despre o problemă a două stări aflate în contradicție, și anume visul și realitatea. El afirmă faptul că realitatea absolută sau suprarealitatea poate fi cheia pentru rezolvarea acestei probleme. De asemenea Breton vorbește despre acea stare de veghe, caracteristică poeziei onirice, și, spune el: sunt obligat s-o consider un fenomen de interferență.. Trecerea de la negație la afirmație și căutarea soluțiilor pentru a scoate poezia din criză au devenit o prioritate pentru suprarealiști ${ }^{7}$. Astfel atotputernicia visului, jocul dezinteresat al gândirii eliberate de constrângeri, explorarea subconștientului, s-au transformat în bucăți de puzzle în vederea soluţionării acestei crize.

Breton afirmă că:

„Trăim încă sub domnia logicii(...). Dar procedeele logice, în zilele noastre, nu se mai aplică decât la rezolvarea unor probleme de interes secundar. Raționalismul absolut care rămâne la modă nu permite să luăm în considerație decât fapte ce se referă strict la experienţa noastră. Dimpotrivă adevăratele scopuri ne scapă. De prisos să adăugăm că experiența însăși s-a pomenit închisă între limite stabilite. Ea se învârte într-o cușcă din care ne vine tot mai greu s-o scoatem. Și se sprijină, și ea, pe utilitatea imediată și este supravegheată de bunul simț. Sub culoarea libertăţii, sub pretextul progresului am ajuns să gonim din spirit tot ceea ce poate fi taxat, pe drept sau pe nedrept, drept superstiție, drept himeră; am ajuns să proscriem orice modalitate de căutare a adevărului (...)." (Manifest al Suprarealismului - André Breton).

Rămânând în zona conceptelor de realitate și vis, și apropiindu-ne de perioada postbelică, Octavian Soviany, vobește în cartea sa Cinci decenii de experimentalism. Compendiu de poezie românească actuală. ${ }^{8}$ despre visul care se caracterizează (...) printr-o „,logică simbolică”, instaurând o ordine, un principiu structurant. El afirmă că tocmai această "dimensiune structurantă a visului este factorul esențial al perspectivei pe care o aducea mișcarea onirică drept element de noutate".

\footnotetext{
${ }^{6}$ https://www.scribd.com/doc/26262034/Andre-Breton-Manifestul-suprarealismului pp. 35-46.

${ }^{7}$ Suprarealistii s-au concentrat și asupra conceptelor: hipnoză, delir, demență etc..

${ }^{8}$ SOVIANY Octavian, Cinci decenii de experimentalism. Compendiu de poezie românească actuală. Volumul I.

Lirica ultimelor decenii de comunism., București, Editura: casa de pariuri literare, 2011.
} 
„Principiile de creație formulate de onirici nu se regăsesc însă doar la câțiva autori, situați în stricta contemporaneitate a momentului de apogeu cunoscut de grupul onirist la sfârșitul anilor 60, dimpotrivă, ele sunt unele cu bătaie lungă, capabile să inspire și să susțină orice tentativă de înnoire a ideii de poecitate. În consecinţă multe dintre ele vor fi reluate, peste mai bine de un deceniu (...) confirmându-se astfel continuitatea perfectă care există între diversele momente ale neoavangardismului românesc postbelic."9

Onirismul şi suprarealismul nu sunt nici identice, nici contradictorii, ci complementare, spune Mircea V. Ciobanu în $\mathrm{nr} 4$ al revistei Limba Română. ${ }^{10}$ "(...) oniricul nu exclude câtuși de puțin realul. Ba chiar are nevoie de el. (...) elementele constitutive, de bază, toată configurația, onirismul estetic (structural) și le ia din realitate, nu din vis. Din vis nu ia decât legile pe care le aplică acestor elemente." ${ }^{11}$ Dumitru Țepeneag susține faptul că visul nu este sursă ori obiect, ci mai degrabă un criteriu: „eu nu povestesc un vis (al meu sau al altcuiva), ci încerc să construiesc o realitate analoagă visului”.

Un exemplu de poet care se află în sfera oniricului este Virgil Mazilescu ${ }^{12}$. Octavian Soviany scrie despre Mazilescu cum că poezia lui înseamnă o aventură ce presupune investigarea infernurilor rimbaldiene, și unde subiectul uman este sfârtecat, amputat de el insuşi. ${ }^{13}$ Tot Soviany explică faptul că lirica lui Virgil Mazilescu este una a nonexpresiei care poate cunoaște două modalități, și anume una minimalistă și una a excesului. Astfel, în prima categorie, limbajul aspiră la nimic, în timp ce în a doua, limbajul aspiră la tot (,Poetizarea mazilesciană va urma, în prima ei fază, modalitatea rimbaldiană a excesului. "). ${ }^{14}$ Poezia lui Mazilescu se legitimează prin încifrarea sensurilor, acestea putând fi decodificate doar printr-un efort hermeneutic ${ }^{15}$, spre exemplu în poemul mai ești orașul în care descifrez străzile, din volumul $O$ precizie cu adevărat

\footnotetext{
${ }^{9}$ Ibid. p. 54-57.

${ }^{10} \mathrm{http}: / /$ www.limbaromana.md/index.php?go=articole\&n=2843, SUPRAREALISM ŞI ONIRISM SAU LEONID DIMOV ŞI TEXTUL DE PL C̆CERE.

${ }^{11}$ ȚEPENEAG Dumitru, SIMUȚ Ion, Clepsidra răsturnată. Convorbiri cu Ion Simuț, București, Editura Paralela 45, 2003, p. 141.

${ }^{12}$ Debut: Versuri (1968), Fragmente din regiunea de odinioară (1970- poeme în proză), Va fi liniște va fi seară (1979), Guillaume poetul şi administratorul (editat 1983). Postume: Întoarcerea lui Immanuel (1991), Poezii (1996), Opere complete (2003), Opera poetică (2013).

${ }^{13}$ Soviany, op. cit., p. 110.

${ }^{14}$ Soviany, op. cit., p. 114.

15. Iulian BOLDEA - Virgil Mazilescu și Scepticismul Oniric. http://www.diacronia.ro/ro/indexing/details/A25180/pdf,
} 
inspăimântătoare ${ }^{16}$ : „mai ești orașul în care descifrez străzile/ cu siguranța unui scamator al plimbărilor/ și animal fericit am strigat pe stadioane/ în care visător mă desfrunzesc la vremea galbenă a lunii/ acum simt că picioarele mi-au devenit/ o reîntoarcere de zi cu zi/ într-un ospăț universal căci în repedea existență cine/ ar ști să profite cuviincios de propria-i naștere. ${ }^{17}$ ”, Interesant este faptul că poetul scrie anumite cu versuri cu scopul de a împărți totul în două, lucru pe care îl vom vedea mai târziu și în poemele Norei Iuga. Spre exemplu în primul poem: nuia de cremene și uneori de zahăr ${ }^{18}$ din volumul amintit: „o fereastră este deschisă în stânga/ o fereastră este deschisă în dreapta” sau poemul coline verzi: ,în stînga am cuvintele în dreapta am puterea"19. Virgil Mazilescu trebuie privit, însă, nu doar ca un poet al limbajului, oricât de incifrat ar fi, ci şi ca un poet al fiinţei: „vei auzi din nou: fii inima mea/ simplu: deschizi doar niște canale/ care din obișnuință nu mai duceau nicăieri/ apoi ị̂ti arzi hainele/ o piele febril descheiată/ încă om/ mâine poimâine doar mărturia lui poate amintirea/ cu haosul ei frățesc: și mai mic uriaș/ așadar aşadar devii a doua mea inimă/ apropie-te/ la toate acestea ce vei răspune? fără un cuvânt/ vei părăsi la noapte orașul/ și absența ta: o cicatrice pe un perete de aer/ micșorându-se din ce în ce din ce în ce”. ${ }^{20},(. .$.$) În versurile lui Virgil Mazilescu se contopesc,$ până la indistincţie, atitudini lirice diverse, de la recursul la acoladele ludicului, imaginarului şi ale oniricului scepticist, până la reflexele cotidianului (...) ori ale autoreflectării şi jocului intertextual, sau la dinamica unei percepţii metafizice asupra lucrurilor."21

Trecând la un alt poet care stă sub semnul oniricului, şi anume Nora Iuga ${ }^{22}$, aceasta, prin scrierile ei, ne face să experimentăm un alt tip de poezie. Iată prin ce cuvinte ni se adresează poeta: M-am născut dintre conjuncția dintre un ochi de miel şi o furculițăa asta ca măcar să simțiți, dragii mei, dacă tot nu ințelegeți că vă iubesc la nebunie când spuneți: „, Merge și așa!”, ca și cum v-ar intra pe fereastră marele necunoscut... În numeroase poeme, Nora Iuga

\footnotetext{
${ }^{16}$ MAZILESCU Virgil, O precizie cu adevărat înspăimântătoare, București, Editura Tracus Arte, 2013, Volum ilustrat de Mircea Dumitrescu.

${ }^{17}$ Ibid. P. 13.

${ }^{18}$ Ibid. P. 5.

${ }^{19}$ Ibid. P. 79.

${ }^{20}$ MAZILESCU Virgil, Opera poetică, ediţie îngrijită şi prefaţă de Gabriel Nedelea, Craiova, Editura Aius, 2013, p. 284

${ }^{21}$ Iulian BOLDEA.

${ }^{22}$ Volume de poezie: Captivitatea cercului (1970), Scrisori neexpediate (1978), Opinii despre durere (1980), Inima ca un pumn de boxer(1983), Piaţa cerului (1986), Cântece (1989), Dactilografa de noapte (1996), Capricii periculoase (1998), Spitalul manechinelor (1998), Autobuzul cu cocoşaţi (2001), Fetiţa cu o mie de riduri (2005), Petrecere la Montrouge (2012), Cainele ud e o salcie (2013), Harald și luna verde (2014), Ascultă cum plâng parantezele (2016).
} 
transformă pur și simplu cotidianul în obiectul ei de joc. De pildă în poemul așa da. e altceva, din volumul ascultă cum plâng parantezele $e^{23}$ : „un voiajor. un domn înalt. venea să mă vadă / tot astfel. pe sub felinare. pe străzile orașului./ trecea încet un ghețar." Sau în poemul când bate în poartă: „dezleg șireturile cadeților. venele albastre/ se varsă în mare. e un tablou gata de somn/ iar tị-ai pus pijamaua pe dos. tocmai acum/ când bate în poartă. o pasăre moartă ${ }^{24 \%}$. Tot în volumul menționat, poeta creează imagini precise pentru a împărți totul în două (așa cum am văzut la Virgil Mazilescu), de pildă în poemul pe limba mea aleargă un cal: „le spun poezii. nimeni nu râde. nimeni nu plânge./ pe limba mea aleargă un cal. în galop. dacă e alb ninge. dacă e negru. are un picior cangrenat." ${ }^{25}$ sau în poemul sute de degete: „bărbații în dreapta. femeile în stânga." ${ }^{26}$ sau „cu pixul galben scriu negru./ cu pixul gri scriu albastru”27. Octavian Soviany vorbește în dreptul poeziei lui Nora Iuga despre o sensibilitate mai degrabă barocăa încercând să „compenseze prin spectacolul feeric sentimentul unei fragilități ontologice care generează sarabada imaginilor, pusă sub semnul dinamismului absolut și al veșnicelor metamorfoze." Despre volumul Cântece, el explică ce se ascunde de fapt în spatele jocului, în spatele universului cotidian care este obiectul jocului, și anume o percepție acută a destrămării. Dincolo de dispoziția de a oniriza, de a gusta din bucuria jocului există în poezia Norei Iuga, spune Soviany, o zonă gravă.$^{28}$ Această zonă se poate evidenția în poeme de tip autobiografic, de pildă poemul VI din volumul inima ca un pumn de boxeur ${ }^{29}$ : „tata a fost muzicant/ mama a fost balerină/ în banca întâi/ mereu în banca întâi/ mușcam dintr-o poezie/ ca dintr-o turtă dulce/ am văzut oameni săpând printre trandafiri/ am văzut trei eleve pieptănate la fel/ se pot observa urme ciudate/ pe bordura trotuarului/ ca pe circumferințele/ unei cești îndelung folosite" ${ }^{30}$. Poezia Norei Iuga este o poezie biografică în măsura în care experienţa intimă e tradusă prin imaginile unui univers haotic, straniu, care devine o ,, lume personală”. ${ }^{31}$

În concluzie, putem spune că fenomenul avangardist promovează o gândire fără prejudecăți ori limite, în care scriitorul poate explora orizonturi de creativitate cu totul noi, așa

\footnotetext{
${ }^{23}$ IUGA Nora, ascultă cum plâng parantezele, București, Cartea Românească, 2016, p.56.

${ }^{24}$ Ibid. P.23.

${ }^{25}$ Ibid. P.15.

${ }^{26}$ Ibid. p. 9.

${ }^{27}$ Ibid. P. 37.

${ }^{28}$ Soviany, op. cit., pp. 159-165.

${ }^{29}$ IUGA Nora, Inima ca un pumn de boxeur, București, Editura Casa de pariuri literare, 2015.

${ }^{30}$ Ibid. p. 19.

${ }^{31}$ http://www.litero-mania.com/lumea-personala-a-norei-iuga/, Raul Popescu.
} 
cum au făcut și poeții menționați, de altfel. Atât poemele lui Virgil Mazilescu cât și cele a Norei Iuga (ambele fiind sub mantaua onirică), ilustrează ideea de libertate în ceea ce privește gândirea poetică și poezia, în ciuda contextului politic și literar în care se aflau.

Student: Dordea Daniela-Elisabeta

Facultatea de Litere și Arte, Anul III

BIBLIOGRAFIE

CĂLINESCU Matei, Cinci fețe ale modernității, București, Editura: Polirom, 2017.

IUGA Nora, Inima ca un pumn de boxeur, București, Editura Casa de pariuri literare, 2015.

IUGA Nora, ascultă cum plâng parantezele, București, Cartea Românească, 2016.

POP Ion, Avangarda în literatura română, București, Editura: Atlas, 1999.

SOVIANY Octavian, Cinci decenii de experimentalism. Compendiu de poezie românească actuală. Volumul I. Lirica ultimelor decenii de comunism., București, Editura: casa de pariuri literare, 2011.

ȚEPENEAG Dumitru, SIMUȚ Ion, Clepsidra răsturnată. Convorbiri cu Ion Simuț, București, Editura Paralela 45, 2003.

MAZILESCU Virgil, Opera poetică, ediţie îngrijită şi prefaţă de Gabriel Nedelea, Craiova, Editura Aius, 2013. 
MAZILESCU Virgil, O precizie cu adevărat înspăimântătoare, București, Editura Tracus Arte, 2013, Volum ilustrat de Mircea Dumitrescu.

\section{RESURSE WEB}

Dicționarul avangardelor - dicteul automat - Rodica Ilie. Disponibil pe internet la adresa: http://www.revistaastra.ro/literatura/files/2013/01/rodica-ilie1.pdf

Revista Contimporanul, (nr. 46) 11 mai 1924, Manifest activist către tinerime. Disponibil pe internet la adresa:

http://dspace.bcucluj.ro/bitstream/123456789/13603/1/BCUCLUJ_FP_P2960_1924_003_0046.pdf

Revista Limba Română. Mircea V. Ciobanu: Suprarealism şi onirism sau leonid dimov şi textul de plăcere. Disponibil pe internet la adresa:

http://www.limbaromana.md/index.php?go=articole\&n=2843

Breton ANDRÉ , Manifest al suprarealismului. Disponibil pe internet la adresa: https://www.scribd.com/doc/26262034/Andre-Breton-Manifestul-suprarealismului

Iulian BOLDEA - Virgil Mazilescu şi Scepticismul Oniric. Disponibil pe internet la adresa: http://www.diacronia.ro/ro/indexing/details/A25180/pdf,

„Lumea personala” a Norei Iuga - Raul Popescu. Disponibil pe internet la adresa: http://www.literomania.com/lumea-personala-a-norei-iuga/ 